\title{
A VIVÊNCIA EM ARTE CONTEMPORÂNEA NA EDUCAÇÃO DE JOVENS E ADULTOS
}

\author{
Aline Martinez Delalibera*
}

\begin{abstract}
RESUMO: O presente estudo discute os momentos de vivências práticas como complementação à inclusão de conteúdos da arte contemporânea nas aulas de Arte da Educação de Jovens e Adultos (EJA) do município de Franca - SP. Este estudo articula os Parâmetros Curriculares Nacionais da disciplina de Arte a referenciais teóricos no campo do ensino, de modo a enfatizar o papel da arte contemporânea como provocadora de participação, reflexão e experimentação junto ao espectador. Partindo desta perspectiva teórica, através de um relato de experiência da vivência prática com os alunos do Ensino Fundamental e Médio da Educação de Jovens e Adultos na Escola Municipal Prof. a Nair Martins Rocha, 0 artigo analisa a visita à exposição $30 \times$ Bienal Transformações na arte brasileira da $1^{a}$ à $30^{a}$ edição, em dezembro de 2013. A escolha da exposição ocorreu em razão das obras de artistas brasileiros contemporâneos abordados nas aulas de arte que participaram do evento, possibilitando aos alunos a experimentação, a reflexão e a participação nas obras.
\end{abstract}

Palavras-chave: Arte educação; EJA; Exposições; Arte Contemporânea.

ABSTRACT: This study deals with the discussion of the moments of practical experience, as a complement to the inclusion content of contemporary art in the art classes of the Youth and Adult Education in the city of Franca - SP (Brazil). National Curriculum Standards for Elementary Education and Art discipline of the East show the importance to address in class the different artistic languages, producers and past art and gift products. Contemporary art produces artistic events that cause the viewer participation, experimentation and reflection. From this theoretical perspective, through an experience report of practical experience with the students of Elementary and Secondary Education of the Youth and Adult Education in the school hall Prof. Nair Martins Rocha, the article will discuss the visit to the exhibition "30 x Biennial: transformations in Brazilian art from 1st to 30th edition", in December 2013. The choice by exposure occurred due to the work of contemporary Brazilian artists covered in art classes that participated in the exhibition, enabling students to experimentation, reflection and participation in construction.

Keywords: Art education; Adult education (EJA); Exhibitions; Contemporary Art.

\footnotetext{
Mestranda em Planejamento e Análise de Políticas Públicas pela Universidade Estadual Paulista "Júlio de Mesquita Filho" (Unesp) - Campus de Franca. Docente do Centro Universitário Claretiano de Batatais (CEUCLAR). E-mail: delalibera.aline@gmail.com
} 


\section{INTRODUÇÃO}

A disciplina de arte na Educação de Jovens e Adultos (EJA) muitas vezes é vista como desnecessária pelos alunos, conforme Sonia Carbonnel (2010) afirma. Em um primeiro momento, os alunos questionam a importância desta disciplina no currículo escolar, mas o trabalho bem desenvolvido, que inclui, além de estímulos para a criação e produção de um trabalho artístico, estudos da história da arte, apreciação de manifestações artísticas e a frequência em exposições, contribui para uma efetiva compreensão e valorização da disciplina pelos alunos da EJA. Ainda segundo a autora, o contato com as linguagens da arte em sala de aula proporciona descobertas e aprendizagens que permitem aos alunos o reconhecimento "nas formas de arte conteúdos existenciais que atravessam séculos, sociedades e culturas e que ainda continuam válidos e atuais para cada um de nós" (CARBONELL, p.35, 2010). Este cenário possibilita que os alunos ampliem seu olhar e vivenciem as produções artísticas e culturais não só do âmbito global, mas do local em que estão inseridos. Através do relato com a experiência de visita a uma exposição de arte contemporânea com os adolescentes, adultos e idosos da EJA do município de Franca e embasado em autores como Pierre Bourdieu, Sonia Carbonell, Fayga Ostrower, Gabriela Wilder, Ana Mae Barbosa, entre outros, foi possível analisar algumas das consequências desta experiência com os alunos.

Ensinar arte para adultos passa a ser distinto do ensino para as crianças, pelo fato de ser um público mais maduro, com mais experiência de vida, de modo que a fruição da arte possa passar a ser uma extensão de suas vidas. É comum para os profissionais que trabalham com arte na EJA deparem com situações cotidianas em que o aluno faz relações do que está aprendendo com a vivência que possui. Fayga Ostrower afirma que

A criação é uma conquista da maturidade. Só ela dará ao artista a liberdade de formular novos conteúdos expressivos, de crescente complexidade estilística e sutileza de nuances emocionais. É preciso ver que, desde sempre, desde as cavernas pré-históricas, a arte fala de adulto para adulto. Por 
isto mesmo, as obras têm o poder de nos comover tão profundamente. Elas são a resposta a uma vida vivida. (OSTROWER, 1990, p. 13).

É importante ressaltar que, no ensino com os adultos, diferentemente das crianças, o professor pode trabalhar o bloqueio geralmente presente naquele público, permitindo que o adulto realmente expresse o que está sentindo. Geralmente, os adultos possuem muita dificuldade em utilizar as técnicas, mas muita facilidade em compreender o que é apresentado. A arte os ajuda a compreender e a perceber que existem maneiras diferentes de abordar o mundo e diversas formas de se expressar.

O aluno adulto é um sujeito pleno de experiências vividas, que podem ser consideradas a porta de entrada para 0 conhecimento escolar. É no encontro entre os conhecimentos prévios e os conhecimentos escolares, na relação de troca entre os saberes do educando e os saberes do educador, que ocorrem mudanças significativas nos olhares, tanto do aluno quanto no do professor. É importante investigar como se dá esse trânsito da vida à escola e da escola à vida, para delinear algumas especificidades dos adultos como sujeitos de aprendizagem, como indivíduos que interagem com os diferentes saberes e como pessoas que transformam o olhar sobre o mundo. (CARBONELL, 2010, p.22)

Desenvolver com o aluno adulto o olhar estético sobre as produções artísticas possibilita que possamos investir em indivíduos autônomos que passam a se reconhecer como integrantes e peças importantes da história. Trata-se, portanto, da formação de um sujeito mais curioso, sensível, criativo, intuitivo, pleno e inteiro em sua relação consigo mesmo, com o outro e com o mundo; indivíduos que se sentem livres para se autodeterminar, para orientar seus desejos, para sonhar, conforme Sonia Carbonell afirma (2010):

Como bem se sabe, as condições de letramento oferecidas à grande maioria da população brasileira, bem como a desigualdade que sustenta as próprias diferenças sociais e legitima os mecanismos de exclusão cultural e econômica em nossa sociedade, silenciam muitos dos estudantes adultos. É 
necessário observar mais profundamente esse publico, pelas condições excepcionais que ele reúne para o aprendizado escolar. Por isso, nestes textos, a voz do aluno ocupa um lugar central. (CARBONELL, 2010, p. 23)

Portanto, o contato com as manifestações artísticas é necessário principalmente com os alunos da EJA. Compreendido como fruição estética, este contato possibilita que este sujeito, muitas vezes excluído do contato com as diversas expressões artísticas da sociedade, se empodere e se sinta parte dela. Conhecer a história a arte possibilita a construção de uma identidade social e a sua prática facilita a construção da identidade individual.

\begin{abstract}
A fruição artística nos ajuda a compreender como uma obra de arte conduz ao mundo dos sentidos e da ressignificação de nossas experiências vividas. Ao interpretar um quadro, fazemos uma projeção do sentido da obra e, em seguida examinamos pormenores, que incluem o tema, e os elementos do meio de expressão, as cores, as linhas, as formas, os sons, as texturas. Cada um desses aspectos contém a obra inteira, mas nenhuma deles é capaz de apresentar sua infinitude. A interpretação constrói-se como um exame atento das partes e uma percepção do todo. A pessoa que interpreta um quadro, uma escultura, um poema, etc. Pode adotar inúmeros pontos de vista e pode ter uma serie de intuições que continuamente se complementam e se modificam, e que não têm um fim determinado. Se a obra for suficientemente significativa, poderemos continuar a construir sentidos e a enriquecer a experiência. (CARBONELL, 2010, p.30)
\end{abstract}

As obras de arte necessitam que os espectadores participem e deem significado ao mundo, além da importância de que encontrem e partilhem sentidos para suas experiências vividas. No entanto, a obra não deve ser apenas algo que tenha identificação pessoal, mas sim algo cujo efeito de seu contato produza, no individuo, uma relação social e que o seu significado seja compreendido por todos. A arte contemporânea, produzindo manifestações artísticas que provocam no espectador participação, experimentação e reflexão, ressalta a vivência em arte como complementação dos conteúdos vistos em sala de aula. Conforme afirma Miriam Celeste Martins (1998), esse 
processo é importante para que leituras significativas sejam produzidas pelos alunos. Ana Mae Barbosa (2009) também apresenta a importância em abordar a arte contemporânea em sala de aula objetivando que os alunos produzam relações com o mundo em que estão inseridos e compreendam melhor os propósitos das obras de arte contemporânea.

\title{
VISITAS ÀS EXPOSIÇÕES CULTURAIS
}

As saídas para visitar exposições, shows de música, teatro e dança são práticas que complementam a educação estética para os alunos de EJA, pois, segundo Carbonell (2010), são grandes oportunidades para que os alunos tenham contato direto com a arte em sua forma genuína. Essas visitas também "apresentam" esses espaços a um público que dificilmente iria frequentá-los: infelizmente, porque os mesmos não se sentem parte destes espaços. 0 próprio público de alunos da EJA ainda preserva um preconceito com a arte, entendendo que os espaços de exposições (museus e galerias), teatros e centros culturais são apenas voltados para a elite.

\begin{abstract}
Muitos locais, principalmente os institucionais, como museus e alguns teatros mais sofisticados, dificilmente serão frequentados pelo aluno da EJA se a escola não realizar uma mediação. São lugares que, em sua maioria, encerram as artes canônicas, não familiares aos alunos trabalhadores. $\mathrm{Na}$ verdade, representam espaços onde eles se confrontam com a própria exclusão social.

Por isso é que museus e espaços de cultura precisam ser dessacralizados pelos professores, para que os estudantes usufruam do universo de encantamento e conhecimento que esses lugares ocultam, para que com essa pratica passem a cultivar o gosto estético. (CARBONELL, 2010, p.40)
\end{abstract}

Ao sair com os alunos do espaço das salas de aula, muitos valores estão incluídos, não apenas os valores culturais, mas também os sociais e os de lazer. É possível perceber que, ao sair, os alunos se preparam para um acontecimento, fazendo com que a aprendizagem seja múltipla e não apenas direcionada para a arte. Promover acesso às manifestações culturais é uma 
função da escola, pois, conforme afirma Bourdieu (2003), os bens culturais acumulados em cada sociedade pertencem apenas àqueles que possuem meios de se apropriar deles. O sistema escolar, muitas vezes, inclui uns e exclui outros da compreensão de códigos que precisam ser conhecidos para que todos desfrutem das diferentes manifestações culturais. Esta inclusão, contudo, em muitos casos depende da posição socioeconômica em que se encontram os indivíduos. A perspectiva da sociologia da arte apresentada por Bourdieu, portanto, possibilita o entendimento do "gosto" pela arte a partir de sua lógica social própria inserida nas dinâmicas de um "campo" pautado em processos de hierarquização, inclusão e exclusão.

O papel de uma educação visual e estética necessita que esta esteja consequentemente alimentada por visitas a museus, galerias, exposições artísticas em geral, discussões e leituras de obras contemporâneas e experiências estéticas que afetem os sentidos e que sejam significativas. (DELALIBERA, 2015, no prelo)

Ao possibilitar que os alunos da Educação de Jovens e Adultos tenham contato com a arte, alguns tabus podem ser quebrados, como o de que a arte só pode ser acessível a indivíduos pertencentes à elite. Conforme reitera Carbonell (2010), com a vinda da corte de D. João VI para o Brasil, a arte foi historicamente associada à aristocracia, de modo que servia como lazer da elite. Este fato pode justificar 0 preconceito e até 0 não interesse por apreciação de atividades culturais, pela grande maioria dos estudantes de EJA. É possível perceber que os alunos, muitas vezes, não se sentem parte destes espaços e os veem como um local em que é preciso ser "culto" ou ser rico para frequentar. Se pensarmos na realidade das produções contemporâneas, este cenário é ainda mais grave, pois a compreensão e a vivência passam a ser mais escassas, já que raramente as produções contemporâneas são apresentadas em sala de aula ou na mídia.

A dificuldade com o contato de obras de arte contemporâneas também é atribuída por Gabriela Suzana Wilder (2009) em razão de 
Na virada do século XIX e no decorrer do XX, os artistas batalhavam por uma arte, à semelhança das diversas ciências que estavam se delineando, como linguagem autônoma, autorreferente, como as notas de uma melodia, destinada a produzir conhecimentos, sensações e prazer. $O$ resultado foi o isolamento de muitos artistas do contexto social em que viviam e as obras foram se transformando em peças herméticas, apreciáveis apenas por uma elite de especialistas. Essa foi a arte incentivada pelos críticos e divulgada em museus e galerias que, consequentemente, reforçava a distinção de pequenos grupos de conhecedores. (WILDER, 2009, p.22)

Os artistas buscam uma função social para as produções artísticas que envolvem questões ecológicas, industriais, exclusão social, questões de gênero e discriminações. Questões, enfim, que permeiam a sociedade em que estão inseridos. A autora Gabriela Wilder (2009) afirma que as instituições de museus de arte moderna e contemporânea, na atualidade, promovem estudos de formação de novos públicos. O tema é chamado de acessibilidade cultural para as populações marginalizadas, justificando, como uma das missões dos museus, a função social. Trata-se, aqui, de um procedimento em que o objetivo passa a ser uma formação cultural baseada na construção de identidades, por meio do diálogo com o mundo e o seu redor. Na concepção da autora, a definição de cultura pode ser entendida como

[...] um sistema de crenças, valores e comportamentos, a expressão da identidade coletiva do grupo que a produz. De modo que a cultura se nutre das raízes do coletivo, e, portanto, só faz sentido para esse coletivo quando se reporta às suas memórias, passado, costumes, quando as pessoas se reconhecem nos comportamentos, crenças e valores, no imaginário coletivo, os quais respondem às suas necessidades e desejos atuais. (WILDER, 2009, p.77).

Vale ressaltar que os alunos de EJA possuem acesso à cultura, principalmente às manifestações culturais de rua, que são manifestações da arte contemporânea (grafite, performances, entre outros), mas, conforme já dito anteriormente, muitos não as reconhecem como manifestações da arte ou então não se interessam por elas por não se identificarem com elas. 
A questão de identidade cultural é apresentada pelo cientista social Stuart Hall (2000), que entende a importância do pertencer e do "identificar-se" à vida das pessoas. Segundo Hall, trabalhar a ideia de "lugar" é essencial, principalmente, quando se trabalha um lugar especifico e concreto que é conhecido pelos indivíduos. A cultura, em seu sentido sociológico - tal como desenvolvido por Hall -, sempre está ligada a questões de identidade e viceversa, já que o sujeito constrói sentimentos de pertencimento para uma manifestação cultural realizada em um território em que o mesmo possui vínculos.

Gabriela Wilder (2209) afirma que algumas pesquisas indicam que os museus de arte moderna e contemporânea não fazem parte do cotidiano dos grupos marginalizados por questões sociais, culturais e políticas.

\begin{abstract}
É possível perceber que as imagens do contemporâneo não se preocupam em apresentar pureza estilística ou em apresentar soluções inéditas de vanguarda, pois são resultados da intertextualidade, da citação, da cópia, da hibridação e de vários estilos. Ao mesmo tempo cultivam o grotesco, contradizendo conceitos estruturados de beleza. Por isso, muito do que se produz hoje ou se produziu nas últimas décadas desafia a hegemonia das linguagens tradicionais (pintura, escultura e desenho), causando no espectador estranhamento, por se deparar com objetos do cotidiano legitimados como arte. Neste momento, esses objetos provocam desconforto e são realizados inúmeros julgamentos que negam sua natureza artística. Muitas vezes pesquisas dentro do campo da arte abrangem espaços externos como cenários para a ação dos artistas, quebrando a mistificação de que uma obra de arte necessita de salas fechadas, organizadas e limpas para ser apresentada ao público. (DELALIBERA, 2015, no prelo)
\end{abstract}

Gabriela Wilder (2009, p. 26) ainda apresenta que a compreensão da arte contemporânea pode ser entendida como "uma visualização do mundo atual conforme percebido pelo artista - num mundo dominado por imagens carregadas de mensagens de uma cultura massiva, acrítica e homogeneizadora". Nesse sentido, a vivência de espaços que possuem arte contemporânea pode ser entendida como um trabalho de inclusão social, 
possibilitando um processo de construção coletiva e autoestima, valorizando a própria cultura, criando condições para posturas críticas frente ao seu entorno. Sobre a inclusão dos conteúdos de arte contemporânea na escola, Delalibera (2015) acrescenta que:

Dentre os conteúdos abordados na disciplina, a discussão sobre o ensino de arte contemporânea se torna necessária devido à sua forma de manifestação, as linguagens, os conceitos, os diálogos proporcionados, os encontros e os caminhos inusitados que buscam permitir a compreensão e a contextualização por parte dos alunos em formação sobre o mundo em que vivem. Muitas vezes essa manifestação artística não é compreendida, por ser comparada com a estética da arte clássica ou moderna, que se mantém através das mídias, contribuindo para desconsiderar a arte contemporânea. Mesmo existindo correntes teóricas para ensino da arte na escola, ainda vivenciamos atividades aplicadas muitas vezes sem sentido e professores com uma visão retrógrada do ensino de arte. (DELALIBERA, 2015, no prelo)

\section{VISITA À EXPOSIÇÃO $30 \times$ BIENAL - TRANFORMAÇÕES NA ARTE BRASILEIRA DA 1à À $30^{\circ}$ EDIÇÃO}

As bienais de arte de São Paulo são importantes espaços para a apreciação de arte contemporânea. Elas ocorrem em diversos países e possuem como proposta apresentar as atuais tendências da arte produzida. $A$ primeira edição de uma bienal no Brasil foi em 1951 e possibilitou que a população e os artistas brasileiros tivessem contato com as obras produzidas em países da Europa, que até então era o centro da produção artística mundial. Na atualidade, as bienais concentram as produções de artistas contemporâneos, tornando-se, assim, as principais exposições de arte contemporânea. Buscando promover 0 acesso às produções de arte contemporânea aos alunos de EJA do município de Franca, a exposição $30 x$ Bienal - Transformações na arte brasileira da $1^{\underline{a}}$ à $30^{\underline{a}}$ edição foi escolhida.

A mostra 30 x Bienal - Transformações na arte brasileira da 1aa à 30 edição buscou apresentar as relações, contextos e processos que os artistas 
brasileiros e obras estabeleceram como momentos determinantes na história da Bienal, da arte brasileira e também internacional. O curador da exposição, Paulo Venâncio Filho, explica que, sem as bienais, provavelmente a tradição moderna e contemporânea não se estabeleceriam de maneira única na arte brasileira, já que o contato e o confronto com tendências estrangeiras foram importantes para a criação do cenário artístico brasileiro. Segundo ele:

[...] por meio tanto das obras quanto dos artistas da exposição, assim como da coletânea crítica do catálogo, $30 \times$ Bienal busca apresentar as transformações da arte brasileira que ocorreram nas trinta edições - desde a polêmica sobre a arte abstrata que dominou os anos 1950, passando pela nova figuração, pelo experimentalismo e pelo influxo da arte pop nos anos 1960, pela atmosfera conceitual nos anos 1970, pelo retorno à pintura nos anos 1980 e pelas chamadas práticas contemporâneas que se manifestam desde o final do século 20. É o "efeito" Bienal, portanto, visto em sua totalidade: um processo transformador. (VENANCIO, 2013)

Os alunos do Ensino Fundamental e Médio da Educação de Jovens e Adultos da Escola Municipal Prof. a Nair Martins Rocha foram visitar a exposição no mês de dezembro de 2013, no Parque Ibirapuera, na cidade de São Paulo, acompanhados pelos professores de Arte, Geografia e História. O objetivo principal foi propiciar aos alunos o contato com as produções de artistas brasileiros contemporâneos. Alguns desses artistas, aliás, já tinham sido trabalhados em sala de aula durante o semestre. Os professores de História e Geografia foram convidados para possibilitar um trabalho interdisciplinar em que temas relacionados à história e à geografia da cidade de São Paulo foram abordados.

Interessante relatar que a visita à exposição também foi aberta à família destes alunos como meio de promover a integração entre a escola e família dos mesmos. Como muitos deles nunca tinham visitado a capital paulista, a experiência não serviu apenas para possibilitar algum contato com as produções artísticas, mas para oferecer oportunidade de conhecimento da cidade de São Paulo. Vale reiterar que alguns alunos, em um primeiro momento, mesmo conhecendo as produções contemporâneas em sala de aula, 
ficaram assustados com a grandiosidade do espaço expositivo e com as obras que estavam expostas. Mas, após um tempo da vivência, os mesmos passaram a ficar mais relaxados e mais curiosos, buscando compreender as mensagens que aquelas produções artísticas passavam.

Como professora, primeiramente os deixei livres para explorar o espaço e apenas intervia quando era solicitada. $O$ interessante foi que, em determinado momento, os alunos é que estavam explicando e discutindo as produções artísticas com os colegas, com desconhecidos e até mesmo com os monitores da exposição. A experiência foi mensurada com a discussão após o término da visita dentro do parque lbirapuera, em que os alunos puderam expor a opinião sobre o que vivenciaram. Conforme Carmem Lidón Beltrán Mir (2009, p.95) afirma,

Tal como comenta Lorente (1997), a função dos espaços de arte contemporânea transformou-se. O público já não busca admirar objetos que são alheios a sua vida cotidiana, porém que encontrar-se a si mesmo por elementos com os quais se possa identificar. E mais, quer viver experiências que poderíamos situar em paralelo à experiência estética: chegar ao conhecimento pelos sentidos, por meio do sentimento e conduzido pela intuição. [...] Nestes espaços, a arte contemporânea propõe com frequência uma auto-reflexão e, nesse discurso proposicional, nos confronta com uma realidade que, de certo modo, falta considerar, em contraposição ao estilo de vida superficial que a sociedade de consumo nos tem acostumado.

Entrar na dinâmica da arte contemporânea exige interpretar um contexto concreto na busca por significados antes inexplorados, que talvez se materializem em descobertos sobre nós mesmos.

Conforme o relato de alguns alunos, a experiência havia contribuído para um melhor entendimento dos conteúdos e discussões trabalhados em sala de aula. A possibilidade do contato direto com as obras foi importantíssima, pois as mesmas foram pensadas pelos artistas com o objetivo de que efetivamente a participação do espectador acontecesse. Os alunos também relataram que, por levarem alguns familiares, foi possível que um 
vínculo com a arte fosse criado, possibilitando que a família passasse a se interessar por arte e também pelas ações culturais da cidade de Franca.

\section{CONSIDERAÇÕES FINAIS}

A disciplina de Arte possibilita um diálogo muito interessante entre professor e aluno, já que a arte marca acontecimentos históricos, políticos e sociais pelos quais a humanidade passou e está passando. Na Educação de Jovens e Adultos, em um primeiro momento, o trabalho possibilita ao aluno voz para expressar sua opinião. Trata-se certamente de um longo processo, já que muitos alunos não compreendem os objetivos da disciplina no currículo escolar. Portanto proporcionar a educação estética e ampliar o repertório artístico aproxima os alunos das manifestações artísticas que fazem parte do cotidiano dos mesmos e também os ajuda a entender que a arte é fruto de muito trabalho do artista - ou seja, não se trata apenas uma atividade irracional, mágica e ociosa. Essas discussões e atividades, nesse sentido, permite que os alunos observem o entorno, o trajeto da escola ao trabalho, resgatando costumes e tradições culturais, observando a existência de objetos artísticos na própria casa. O contato com uma exposição de arte contemporânea também pode ser um espaço para trabalhar a diversidade, já que as discussões que as produções artísticas promovem não dependem de saberes ou identidades de cada visitante. O conhecimento de várias áreas, juntamente com os conhecimentos da arte, proporciona a inserção do aluno no mundo do trabalho, da cultura e das relações sociais.

\section{REFERENCIAS BIBLIOGRAFICAS}

BOURDIEU, P.; DARBEL, A. O amor pela arte. São Paulo: Edusp, 2003.

CARBONELL, S. Educação Estética para Jovens e Adultos: a beleza no ensinar e no aprender. São Paulo: Cortez, 2010.

DELALIBERA, Aline Martinez. O ensino da arte-educação no ensino fundamental II hoje e sua relação com a estética da arte contemporânea. In: II 
ENCONTRO INTERNACIONAL EM POLÍTICAS PÚBLICAS, n. 2, 2015, Franca. Anais do II Encontro Internacional em Políticas Públicas. Franca: Unesp, Uni-FACEF, 2015. (no prelo)

HALL, S. A identidade cultural na pós- modernidade. Rio de Janeiro: DP\&A, 2000.

MARTINS, M. C.; GUERRA, M. Terezinha Telles; PICOSQUE, G. Didática do ensino de arte: a língua do mundo: poetizar, fruir e conhecer arte. São Paulo: FTD, 1998.

MIR, Carmen Lidón Beltrán. Educação como mediação em centros de arte contemporânea. In: BARBOSA, Ana Mae; COUTINHO, Rejane. Arte/educação como mediação cultural e social. São Paulo: Editora Unesp, 2009. p. 85-102.

OSTROWER, F. Acasos e criação artística. Rio de Janeiro: Campus, 1990. VENANCIO FILHO, P. Apresentação. 2013. Disponível em: <http://www.30xbienal.org.br/single/apresentacao/>. Acesso em: 1 dez. 2015.

WILDER, G. S. Inclusão social e cultural: arte contemporânea e educação em museus. São Paulo: Editora Unesp, 2009.

As artes visuais do século XX como visão de mundo e exercício de diversidade. Inclusão cultural: uma missão de museus de arte contemporânea. Tese (Doutorado em Ciências da Comunicação) - Escola de Comunicações e Artes, Universidade de São Paulo, São Paulo, 2004. 